\title{
Remote Sensing Global Ranged Door Lock Security System via Mobile Communication
}

\author{
Md Mostafizur Rahman Komol ${ }^{\mathrm{a}}$, Amit Kumer Podder ${ }^{\mathrm{b}, *}$, Abdullah Arafat ${ }^{\mathrm{c}}$ and Tanzim \\ Nabeed ${ }^{\mathrm{b}}$ \\ ${ }^{a}$ Department of Mechanical Engineering, Khulna University of Engineering \& Technology, Khulna, \\ Bangladesh \\ ${ }^{b}$ Department of Electrical and Electronic Engineering, Khulna University of Engineering \& Technology, \\ Khulna, Bangladesh \\ ${ }^{c}$ Department of Material Science and Engineering, Khulna University of Engineering \& Technology, Khulna, \\ Bangladesh
}

Received: 23 May 2019; Accepted: 09 August 2019; Published: 08 September 2019

\begin{abstract}
In this paper, a door locking system with some remarkable features is proposed which makes the locking or unlocking of a door more reliable to the user than the conventional system. Robust security access with accurate detection system is provided here. It's a global ranged operation process that can be operated by simple mobile phone through short message service (SMS) transferring operation from any corner of the world where mobile network is available. A smooth and durable locking mechanism is provided and the inscrutable door moving control device is used for the efficient operation of controlling the door. This developed system provides a notification to the user if any person is intended to pass the door. The system also has the ability to provide information about the current condition of the door by sending simple text messages. Also, the user will be able to operate the system with more than one subscriber identity module (SIM) card. Most advantageously, this device is proposed with lowest cost estimation benefit. Finally, the performance of the designed system is analyzed by performing some real-time operation of it and found satisfactory performance.
\end{abstract}

Index Terms: Door lock security system; arduino; servomotor, mobile communication; GSM module

(C) 2019 Published by MECS Publisher. Selection and/or peer review under responsibility of the Research Association of Modern Education and Computer Science

\footnotetext{
* Corresponding author.

E-mail address: amitpodder09@yahoo.com
} 


\section{Introduction}

Modern lock refers to a system which gives the highest security and flexibility for locking of secure door or vault [1]. However, operating door lock through a distance has a great advantage nowadays. Peoples are often busy at work, so they cannot go every time to unlock the door lock of secure places for other. Also, people often forget or lost their keys [2-5]. And also, they cannot keep their eye on their door all the time but by a smart locking system, they will be notified every time after detecting the presence of an object near vault or door.

Wireless communication technologies have attained massive public favour and so getting widespread as ubiquitous. It dispense with sundry blissful features like dense reliability, economic, effortless handling, swiftly in speed, and no strenuous connection between disparate devices [6-9]. The locking system presented here will permit the user to unlock and lock the vault or door from anywhere in the world under GSM network through the cell phone via text message. Cellular mobile technology is advancing day by day rapidly. The evolution of mobile technology starts with zero generation $(0 \mathrm{G})$ technology and now advances to fifth generation (5G) technology. The different generation technologies $(0 \mathrm{G}, 1 \mathrm{G}, 2 \mathrm{G}, 4 \mathrm{G}, 5 \mathrm{G})$ provide different standards. Among the $2 \mathrm{G}$ mobile communication standards, global system for mobile technology (GSM) is considered most dominant. Nonetheless, the new $3 \mathrm{G}$ and $4 \mathrm{G}$ standards are bestowed with high penetration; GSM system is prevalent in offering voice services in remote areas and access low and medium data rate services everywhere at cheap rate [10]. Apart from the recently available 4G technology, the 5G technology also promises higher data rates at a cheaper rate. The mostly available 4G technology based GSM system is utilized in the proposed work. There is another feature of this lock which makes it one step more advance and that is smartly lockable to send a text message to the predetermined user's number after detecting the presence of an object near it. Therefore, this locking system will bring the door to user's hand and keep an eye and operating door will be more comfortable if someone adopts this locking system.

The basic component of this locking consists of an Arduino device which works as a microcontroller unit and a GSM module which will connect to the GSM network. Another vital component is light dependent resistor (LDR) sensor directly connected with the laser beam from laser emitter. This system will detect the presence of an object and send the signal as a text message to vault owner through GSM module. The whole system is implemented with the proper electrical connection. The computer-aided design (CAD) of the locking system is also presented for showing the locking and unlocking of the door. The performance of the system is checked by operating it in real-time which shows a better response. Whole system is managed to produce with lowest cost possible and a detail explanation is provided for commercial production of this proposed system. In summary, the main contributions of this research work are:

- For a reliable and durable security, a user friendly locking system has to be proposed. In this paper, a robust security access with accurate detection system for a door is provided.

- Implemented a SMS based security system that is user friendly and easy to operate and learn.

- Developed a platform for improvising and innovation in SMS based door locking system with low cost, robustness and reliability.

\section{Background}

In recent years, many works on door lock security system have been done. Various authors and researchers all around the world present various works on modifying the door lock security system. Numerous papers are studied and the contribution has been enlisted in Table 1. The latest related works are reviewed in order to present the recent progress of door lock security system. It is seen that the door lock security is provided or implemented using various digital technologies like GSM, peripheral interface controller (PIC), general packet radio service (GPRS), radio frequency identification (RFID) system, dual tone multi-frequency (DTMF) based 
GSM system and so on. Apart from the presented works in Table 1, some other door locking system based on biometrics, GSM, one-time password (OTP), cryptography etc. are developed [14-17]. In some cases, the security system is provided for robust and implacable security but having high cost, in other cases the cost is optimized by providing less implacable security system. Therefore, how the security system will be designed mostly depends on the application of it. In the research work, the door lock security is designed for a vault door application i.e. the door can be used as the vault door of a jewellery shop or domestic locker. Therefore, to protect the available utensils, the implacable door security is not only essential but also the locking system should be low cost so that the domestic user can use the system. That's why having considered all the related works on door lock security system as presented in Table 1, a remote sensing global range door security system is designed utilizing GSM based mobile communication system.

Table 1. Related works on security system of door locking

\begin{tabular}{|c|c|}
\hline Author & Contribution \\
\hline $\begin{array}{l}\text { A. Ibrahim, A. Paravath and } \\
\text { P.K. Aswin [1] }\end{array}$ & $\begin{array}{l}\text { Designed and implemented a digital system of door locking which is based on GSM and PIC } \\
\text { platform. }\end{array}$ \\
\hline Y. Zhao and Z. Ye [2] & $\begin{array}{l}\text { Implemented low power consumption, low cost wireless home security system which is based on } \\
\text { GSM/GPRS and used three kinds of sensor nodes of wireless security. }\end{array}$ \\
\hline $\begin{array}{l}\text { U.J. Orgi, D.E. Bassey and A. } \\
\text { Etim [3] }\end{array}$ & $\begin{array}{l}\text { Implemented a remotely controlled security door that can be operated by a GSM phone set which } \\
\text { is acted as the transmitter and a door motor connected to another dual tone multi- } \\
\text { frequency(DTMF) based GSM phone set through a DTMF decoder which is interfaced with a } \\
\text { stepper motor and microcontroller unit. }\end{array}$ \\
\hline P. Mishal, et al[4] & $\begin{array}{l}\text { Implemented security system at homes, offices that will lock the door automatically by receiving a } \\
\text { previously defined message which is sent by the user. }\end{array}$ \\
\hline $\begin{array}{l}\text { G. K. Verma and P. Tripathi } \\
\text { [11] }\end{array}$ & $\begin{array}{l}\text { Implemented a door locking security system using passive type of RFID which can be activated } \\
\text { and authenticated by the user and for secure access the door can be unlocked in real time. }\end{array}$ \\
\hline H. Hassan, et al [12]. & $\begin{array}{l}\text { Developed a face recognition system based Graphical User Interface(GUI) and a automatic } \\
\text { switching magnetic lock which is generated by peripheral interface controller(PIC) for door lock } \\
\text { security system. }\end{array}$ \\
\hline J. Johnson and C. Dow [13] & $\begin{array}{l}\text { Implemented an intelligent door lock system that has a remotely operable lock at a dwelling } \\
\text { accessible by a user. }\end{array}$ \\
\hline
\end{tabular}

\section{Design and construction of the system}

\subsection{Design Consideration}

For the implementation of this system, a frame is considered which is having one door and five units. They are: (i) Locking mechanism (ii) Door moving device (iii) Detector unit (iv) GSM unit and (v) central control unit. Firstly, the locking mechanism unit consists of a servo motor and a metallic hatch lock linked with gear. Secondly, door moving device comprises a servo motor and a sliding aluminum bar. The detector unit composed of laser and LDR connection of strong sensing. GSM unit consists of GSM module with active SIM card. Finally, the central processing unit includes a microcontroller, Arduino Uno. The proposed design also consists of a cell phone where the SMS is sent from the GSM module. The command is given by cell phone via SMS system with a secret password which will reach the GSM module. GSM provides the signal to the central processing unit. In the central processing unit, the microcontroller operates according to the program installed in it and verifies the password with the password given in the program. If it is ratified, it commands the motor unit to operate the door to be opened. Otherwise, it doesn't command the motor unit to rotate to let the door open. LDR in direct contact with a laser beam from laser emitter is used here as a detector unit to sense the 
presence of the person and detect it and lock the door automatically if a person leaves the door. Manual locking system via SMS is also provided. The mechanical coupling with electric circuit completes the entire design. The dimensions of the system are shown in the following Fig. 1. The remote sensing global ranged door lock security system consists of two servo motor, one Arduino Uno, a global system for mobile communication (GSM) module, a DC power supply, a laser emitter and a light dependent resistor (LDR) sensor. The specification of the component used in the system is given below.

\subsubsection{Arduino Uno}

Arduino Uno is used here as microcontroller system. It is a venture that can control and detect physical gadgets. The UNO version of it is utilized here as a miniaturized scale controller gadget for working the capacity of door lock system.

\subsubsection{Servomotor}

Two servomotors are used here. The power is supplied to servomotor through an external adapter. All the gears of it are metal. The operating speed and a stall torque of it are $0.17 \mathrm{sec} / 60$ degrees $(4.8 \mathrm{~V}$ no load) and 13 $\mathrm{kg}-\mathrm{cm}(180.5 \mathrm{oz} .-\mathrm{in})$ at $4.8 \mathrm{~V}$ respectively. The $4.8-7.2 \mathrm{~V}$ is considered as operating voltage.

\subsubsection{SIM Card}

A subscriber identification module (SIM) is an incorporated circuit chip that is planned to safely store the international mobile subscriber identity (IMSI) number and its related key, which are utilized to distinguish and confirm subscribers on mobile telephony gadgets. It is additionally conceivable to store contacts on numerous SIM cards. Here, the utilized SIM card is upheld by GSM arrangement.

\subsubsection{Power Supply}

A 6V DC power supply is used here to supply power to the motor and an adapter is used to supply power to Arduino board. The input voltage of the adapter is $220 \mathrm{~V} \mathrm{AC}$ and its output voltage is considered as 5V DC.

\subsubsection{Laser}

A laser emitter is used here for detecting a person. The laser emitter is placed in consequences so that the laser beam connects directly to LDR sensor. 


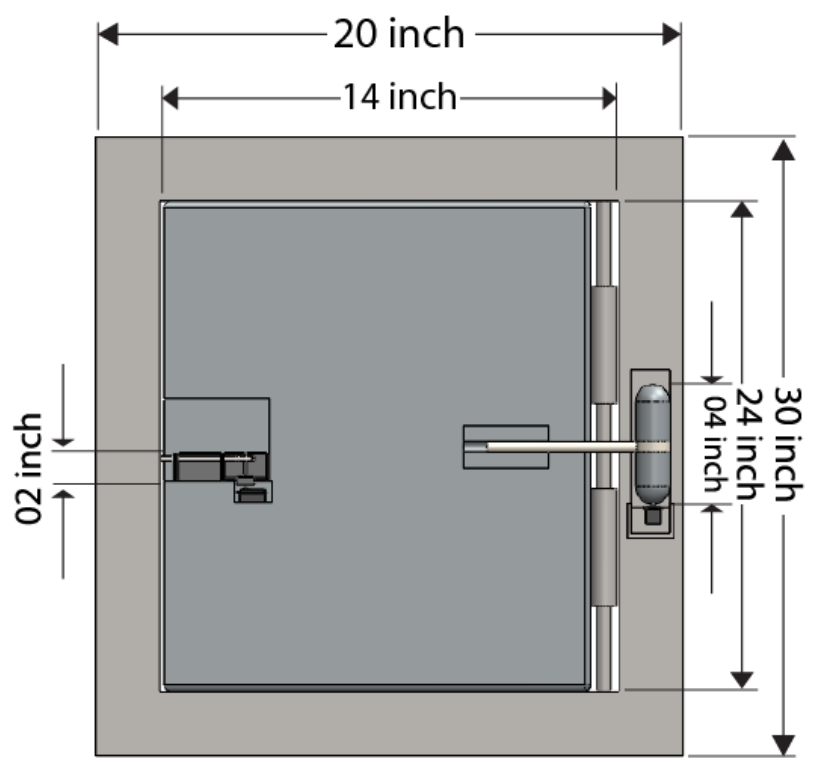

Fig.1. Design and dimensions of the door lock security system.

\subsubsection{Photo Transistor}

An LDR is used here as a phototransistor. It receives a continuous high amount of light from laser emitter and senses the presence of something or someone when the connection of laser beam and LDR interrupted.

\subsection{Electrical Circuit}

In this work, the electrical components of the system are connected according to Fig. 2. The whole system is powered by a 6V DC power supply and also has a battery backup in case of power failure. Servomotor 1 is connected with digital pin 10 and servomotor 2 is connected with digital pin 6 in microcontroller Arduino Uno board. A laser emitter is powered and light depending resistor (LDR) pin is attached with Analog pin A1 to get signal from the microcontroller. GSM module SIM 900A is attached with its four pins. TXD and RXD are connected respectively with RX and TX of Arduino. Its ground pin is grounded with Arduino. The DC IN pin is directly connected with $6 \mathrm{~V}$ DC power supply. 


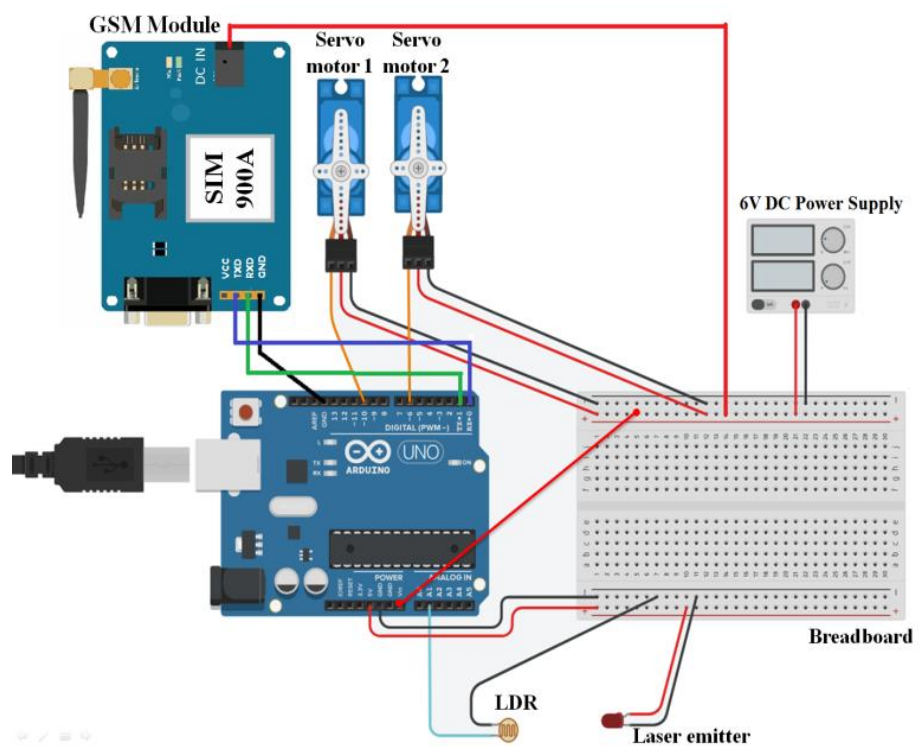

Fig.2. Circuit diagram for the GSM based door lock system.

\subsection{Mechanism of the locking system}

A special hatch lock mechanism is made with iron which penetrates a solid bar into the door to lock the door when engaging with motor's clockwise rotation. It provides better performance than other available door lock and more flexible, sliding, frictionless with strong ensured locking. The mechanism of the locking system is coupled with the servo motor to operate with the action of servo rotation to lock or unlock the door. A strong gear is attached with the servo motor to convert the rotating motion of servo motor into reciprocating motion and provides linear proceeding of locking bar to lock or unlock the door. Computer Aided Design (CAD) design of hatch lock engaged and disengaged is shown in the following Fig. 3. The CAD design of the door moving control device is shown in Fig. 4.

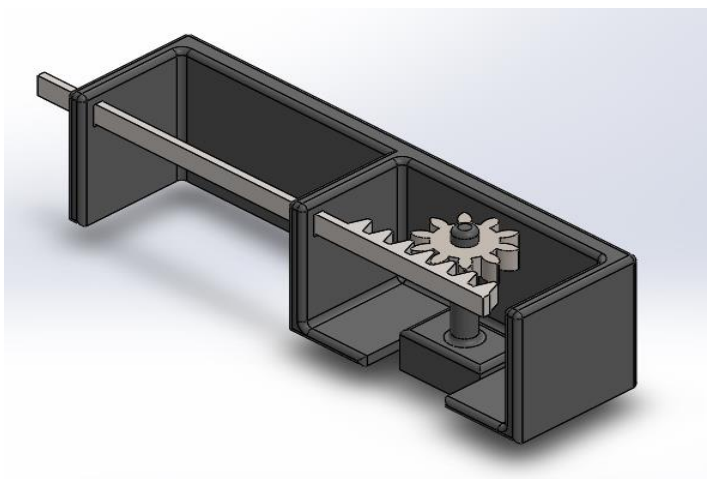

(a)

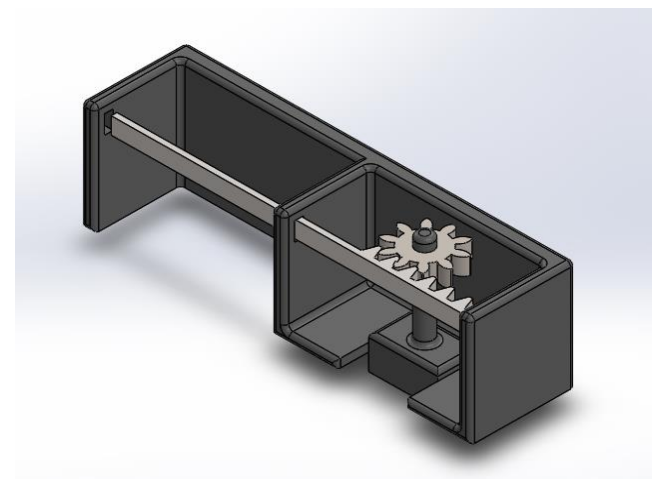

(b)

Fig. 3. CAD design of hatch lock in (a) engaged, and (b) disengaged position 


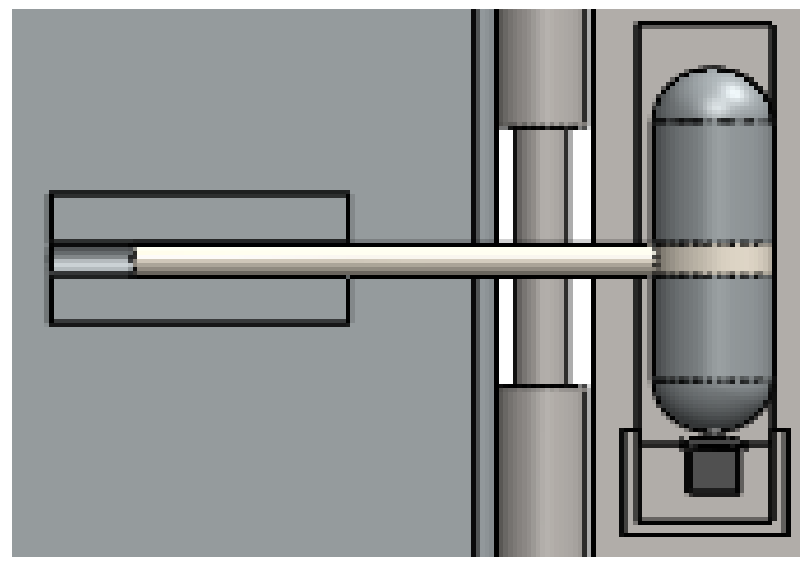

Fig.4. CAD design of door moving control device

\section{Operating methodology of the system}

A flowchart of control of the operation of the door locking and unlocking by sending SMS via mobile phone to GSM unit is shown in the following Fig. 5. As it comprises one LDR sensor where laser beam falls directly from laser emitter, it will recognize anyone presence when someone intended to enter. When a person intended to enter the door must go over the laser and the high-intensity light of laser beam falling on LDR is interrupted. This gives a very lower value in LDR resistance that goes far lower than the threshold value and it will send the signal to the microcontroller unit. When it is initiated, the detecting unit sends a signal through .

GSM shield to the user's mobile phone. The user can likewise enact and deactivate the system through his mobile phone instant message by proper code command. It will give an alert when instant messages are sending to the user. The microcontroller works as the controller of the whole system. It verifies the user cell phone number to avoid unwanted entries. It verifies the input code and converts it into command. It contains all necessary data and programs to maintain operations. It lets the user activate and deactivate the detectors unit. The GSM module connects the user to the door security system by being the medium of sending and receiving text messages. It activates the GSM supported SIM. It has a powerful antenna which helps to catch the network under inappropriate locations. The servomotor used in the system can precisely rotate according to the user's command. If the user sends the command to open the door, it starts to operate the servo motor 1 to unlock the door and disengage the locking bar from the door as shown in Fig. 6(a) and push door to open the operation of servo motor 2 as shown in the following Fig. 6(b). If the user sends the command to close the door, it immediately pulls the door to shut. Servo motor 2 of door moving device operate in the reversed direction to move the door to the previous position as shown in following Fig. 7(a). After the door return to its fixed position, the servo motor 1 rotates to move the locking bar through gear mechanism and lock the door with the frame. It is shown in following Fig. 7(b). 


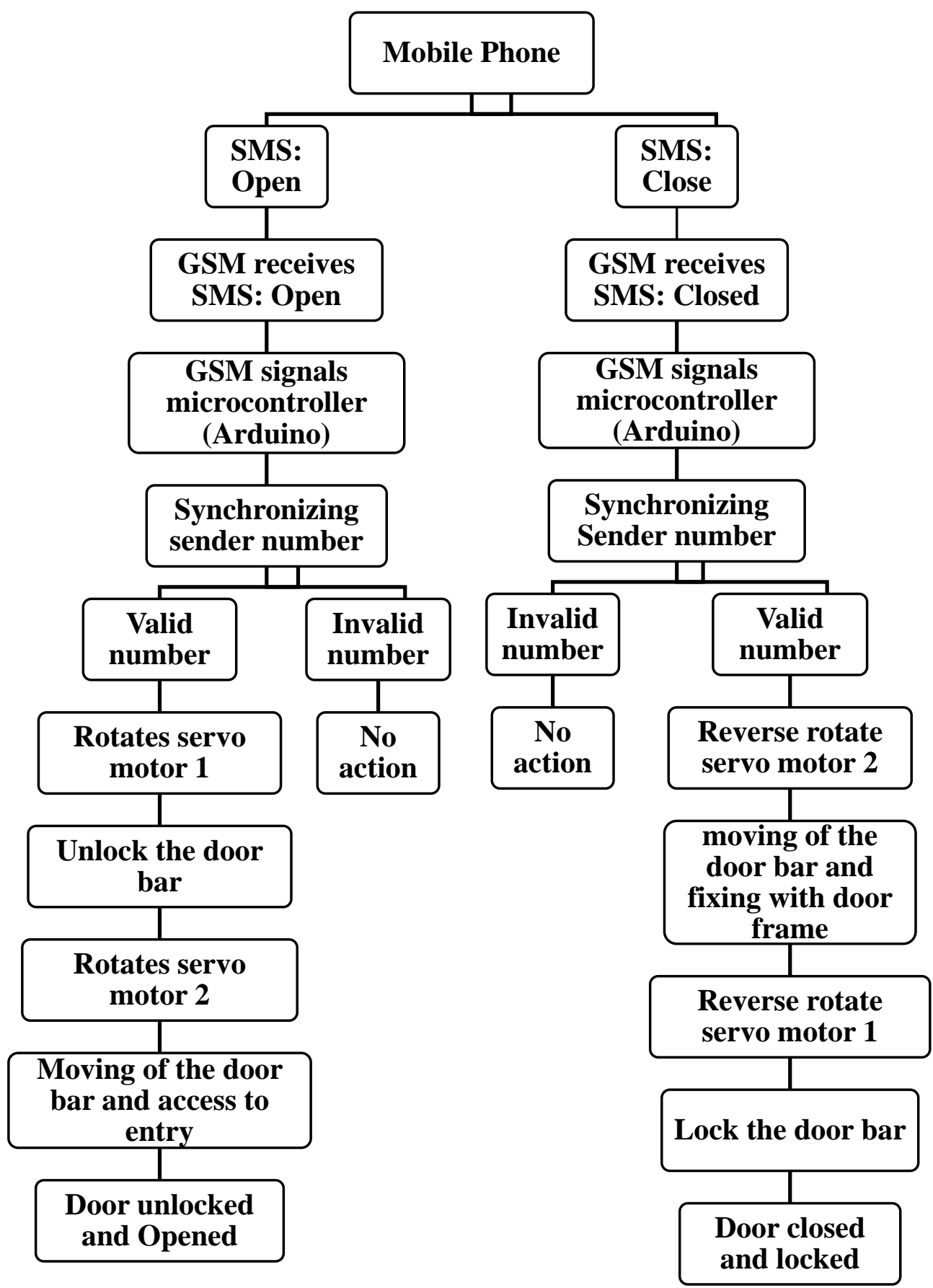

Fig.5. The flowchart of the operation methodology of the proposed door locking system 


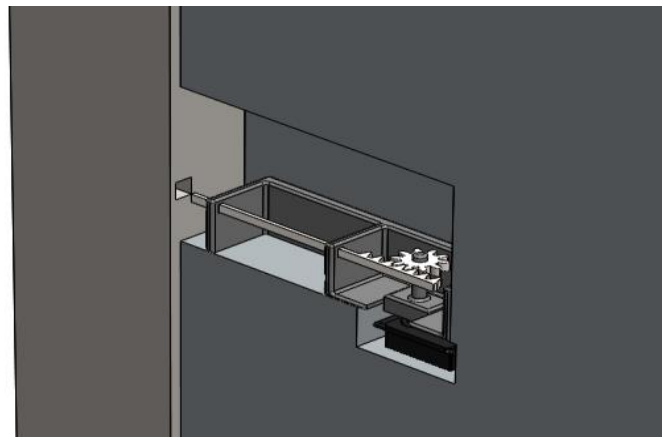

(a)

Fig.6. (a) Unlocking, and (b) Opening of the door bar

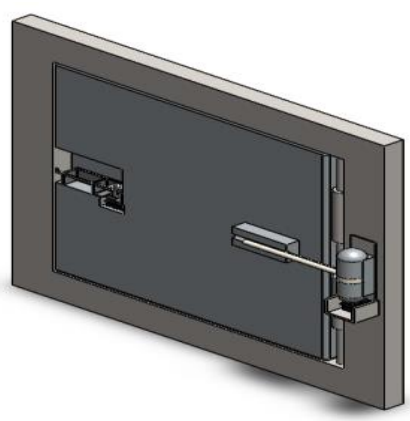

(a)

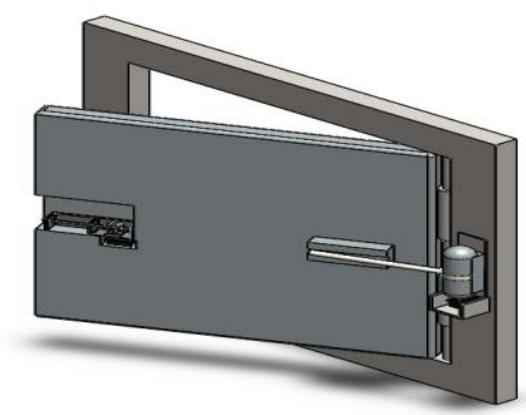

(b)

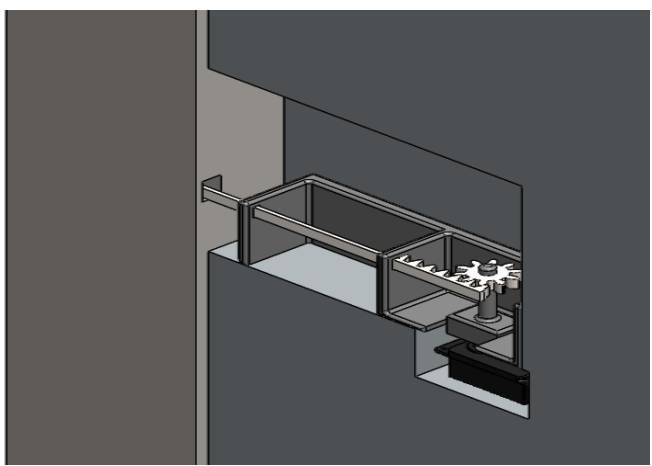

(b)

Fig. 7. (a) Closing, and (b) Locking of the door bar

\section{Performance evaluation and cost analysis}

For the evaluation of the proposed system performance, the following verifications are done. They are described below.

In this work, the system is designed to verify only two service provider's number which is Grameenphone and Banglalink. Only the number +8801787759085 and +8801922107814 are allowed and programmed as the valid number to operate this work. The servomotor used in the system can precisely rotate according to the user's command. If the user sends the command to any number except them is considered as the invalid number. On behalf of invalid number, the number +8801716941716 is used in performance test to clear the verification of number validity. The valid SMS in this research work is used as "Open" to open the door and "Close" to close the door. Any SMS except them is considered as a False keyword in the performance test. Evaluation of number is done by collecting information from GSM module after receiving messages by a particular AT command (AT+CMGR). The information that GSM module provides is almost like a paragraph. Therefore, the whole para is saved on a string. After that, the particular segment of string which contains only sender's number is saved to another string by a simple FOR loop. Then this string is compared with the previously inputted string which contains a valid number of the user. If it seems ok, next operation would continue otherwise it terminates its operation.

Evaluation of keyword is done by collecting information from GSM module after receiving messages by a particular AT command (AT+CMGR). The text messages information is added automatically by the service provider and the information that GSM module provide is almost like a paragraph. Therefore, the whole Para is saved on a string. After that, the particular segment of string which contains only sender's text messages is saved 
to another string by a simple FOR Loop. Similarly, like the verification of number, this string is compared with the previously inputted string which contains a valid keyword. If it seems ok, next operation would continue otherwise it stops its operation because of an invalid keyword. The test for performance is measured 7 times with different numbers and SMS code. The performance test data for different mobile number and SMS keyword is shown in following Table 2.

Table 2. Verification test data for different mobile number and keyword

\begin{tabular}{llllll}
\hline Mobile phone No. & SMS & Input & Verify Status & Door operation & Output \\
\hline+8801787759085 & Open & Open the door & valid number \& SMS & Door opened & Responded \\
+8801787759085 & Close & valid number \& SMS & Door closed & Responded \\
+8801787759085 & $\begin{array}{l}\text { Anything except } \\
\text { "open" or } \\
\text { "close" }\end{array}$ & Not found & False keyword & No action & No response \\
& & & & \\
+8801922107814 & Open & Open the door & valid number \& SMS & Door opened & Responded \\
+8801922107814 & Close & close the door & valid number \& SMS & Door closed & Responded \\
+8801716941716 & Open & Not found & Invalid number & No action & No response \\
+8801716941716 & Close & Not found & Invalid number & No action & No response \\
\hline
\end{tabular}

Comprehensive analysis of cost estimation of the entire project is exhibited in Table 3 . Here, the total cost was calculated summing up the individual component and system assembly expenditure that are illustrated in a tabular form. Cost can be reduced to $65 \%$ if the whole system is produced commercially. The cost of GSM module will be a greater decrease if commercial GSM used in mobile phone is used. Moreover, using an Arduino mini or integrated circuit (IC) with printed circuit board (PCB) system will reduce the cost of microcontroller system as well as prevent the use of breadboard. Hence, there will be a saving of breadboard cost. Furthermore, the commercial production as product will lessen the expenditure on machining, assembly and sequential gear cutting. In addition the cost of door bar with frame will be deducted as it is used here only for experimental purpose. Only the device is to be produced commercially and externally attachable to our individual door bar. In fine, it is predicted that the expenditure to the maximum as a commercial production will be around 2500- 3000 taka only. The cost estimated for the proposed design is compared with [3] and found higher cost than the proposed design.

Table 3. Cost estimation of the components and machining

\begin{tabular}{lcc}
\hline Components & Quantity & Total price (taka) \\
\hline GSM SIM 900A & 1 & 2500 \\
SIM Card & 1 & 100 \\
Arduino UNO* & 1 & 600 \\
Servo Motor & 2 & 700 \\
Breadboard* & 1 & 150 \\
LDR & 1 & 5 \\
Laser & 1 & 50 \\
Battery (6V)* & 1 & 150 \\
Gear making with machining & & 200 \\
Door bar with frame & 1 & 450 \\
Hatch lock assembly & & 150 \\
Door moving control device Making \& & & 350 \\
assembly & & 5405 \\
Total Cost & & \\
\hline
\end{tabular}

*Used for making the demonstration, will be precluded in commercial version. 


\section{Conclusions}

Door security becomes a great issue in this modern era. Every scope of daily life now wants a promising and smooth security system for the door. It would be one step ahead advantage if the door could be operated from a long distance. In this security system, both are achieved. It could be operated from a very long distance even from out of the country from anywhere in the world where GSM network is available. This security system is also promising because it has a remarkably reliable detector unit which sends the notification to the user if someone gets close to the door. The detector unit also gives the full control over the door to the user. The user can get information about the condition of the door by simply sending a keyword by text messages. This system is beneficial to produce commercially at a minimum cost possible to maximum profit.

\section{References}

[1] A. Ibrahim, A Paravath, and P. K Aswin., S M Iqbal and S Usman Abdulla, "GSM based digital door lock security system", IEEE International Conference on Power, Instrumentation, Control and Computing (PICC), Dec. 2015.

[2] Y. Zhao, and Z. Ye, "A low cost GSM/GPRS based wireless home security system", IEEE Transactions on Consumer Electronics, Vol. 54 , No. 2 , May 2008.

[3] U. J. Ogri, D. E. Bassey, and A. Etim, "Design and construction of door locking security system using GSM", International Journal Of Engineering And Computer Science, Vol. 2, No. 7, pp. 2235-2257, July 2013.

[4] P. Misal, M. Karule, D. Birdawade, A. Deshmukh, and M. Pathak, "Door locking/unlocking system using SMS technology with GSM/GPRS services", International Journal of Electronics Communication and Computer Engineering, Vol. 5, No. 4, April 2014.

[5] M. M. R. Komol, A. K. Podder, M. N. Ali, S. M. Ansary. "RFID and Finger Print Based Dual Security System: A robust secured control to access through door lock operation," American Journal of Embedded Systems and Applications. Vol. 6, No. 1, pp. 15-22, 2018.

[6] T. Liu, Y. Liu, Y. Mao, Y. Sun, X. Guan, W. Gong, S. Xiao. "A dynamic secret-based encryption scheme for smart grid wireless communication,” IEEE Trans. Smart Grid, Vol. 5, pp. 1175-1182, 2014.

[7] X. Wang, P. Yi, "Security framework for wireless communications in smart distribution grid," IEEE Trans. Smart Grid, Vol. 2, pp. 809-818, 2011.

[8] N. Langhammer, R. Kays, "Performance evaluation of wireless home automation networks in indoor scenarios," IEEE Trans. Smart Grid, Vol. 3, pp. 2252-2261, 2012.

[9] D. Niyato, P. Wang, "Cooperative transmission for meter data collection in smart grid," IEEE Commun. Mag, Vol. 50, pp. 90-97, 2012.

[10] L. A. G. Gomez, S. C. Pereira, A. L. L. F. Murari, H. S. Franco, A. T. Jose, "Analysis of a Control System for DFIG Wind Generators Based on the Transmission of Power References through a GSM Wireless Network: A Smart Grid Experimental Approach,” Mdpi Journal: Energies. Vol. 12, No. 2, January 2019.

[11] G. K. Verma and P. Tripathi, "A digital security system with door lock system using RFID technology," International Journal of Computer Application, Vol. 5, No.11, pp. 6-8, August 2010.

[12] H. Hassan, R. A. Bakar, A. Thaqib, and F. Mokhtar, "Face recognition based on auto-switching magnetic door lock system using micro-controller," International Conference on System Engineering and Technology, pp. 1-6, 2012.

[13] J. Johnson and C. Dow, "Intelligent door lock system with encryption," US Patent Application Publication Johnson et al., pp. 1-92, June 2016.

[14] M. Meera, R. S. Divya, "Survey on Various Door Lock Access Control Mechanisms", International Conference on circuits Power and Computing Technologies, pp. 1-3, 2017. 
[15] M. Pradnya, R.Nehete and K P Rane, "OTP based door lock security system," International Journal For Emerging Trends in Engineering and Management Research (IJETEMR) Vol. II, No. II, June 2016

[16] A. Chowdhury, "Revolution in authentication process by using biometrics," International Conference on Recent Trends in Information Systems, 2011, pp. 36-41.

[17] T. Vanhuy, D. T. Minh, N. P. Kien, T. A. Vu, "Simple robotic hand in motion using arduino controlled servos”, International Journal of Science and Research (IJSR), Vol. 6, Issue 3, pp. 972-975, March, 2017.

\section{Authors' Profiles}

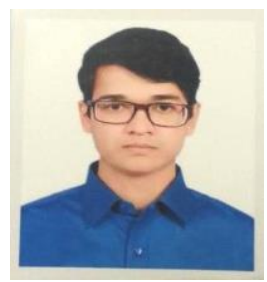

Md. Mostafizur Rahman Komol was born in Bangladesh. He obtained B.Sc. in Mechanical Engineering from Khulna University of Engineering \& Technology (KUET) in 2017. He is ebullient in mechatronics, robotics and manufacturing related research works. His field of interest includes Control engineering, Mechatronics, Aerodynamics, Computational fluid dynamics, Engineering mechanics, Thermodynamics.

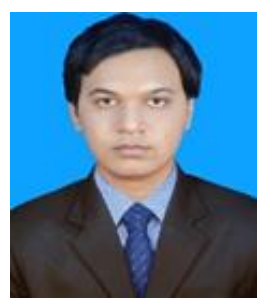

Amit Kumer Podder was born in, Bogra, Bangladesh. He obtained B.Sc. and M.Sc. in Electrical and Electronic Engineering (EEE) from Khulna University of Engineering \& Technology (KUET) in 2016 and 2019, respectively. He is now working as an assistant professor in EEE department of KUET. He has published a number of journals and conference proceedings in international level. His field of interest includes, Mechatronics, Power system stability and Renewable energy.

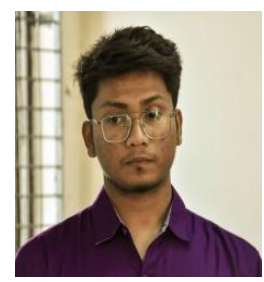

Abdullah Arafat was born in Bangladesh. He is currently a $4^{\text {th }}$ year student in Material Science and Engineering department of Khulna University of Engineering \& Technology (KUET). His field of interest includes Design, CAD design, Material Science.

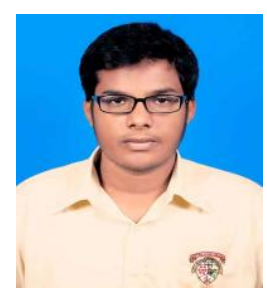

Tanzim Nabeed was born in Dhaka, Bangladesh. He is currently a $4^{\text {th }}$ year student in Electrical and Electronic Engineering department of Khulna University of Engineering \& Technology (KUET). His field of interest includes Electronics, Power system, Complex circuit implementation. 
How to cite this paper: Md Mostafizur Rahman Komol, Amit Kumer Podder, Abdullah Arafat, Tanzim Nabeed, "Remote Sensing Global Ranged Door Lock Security System via Mobile Communication", International Journal of Wireless and Microwave Technologies(IJWMT), Vol.9, No.5, pp. 25-37, 2019.DOI: 10.5815/ijwmt.2019.05.03 